\title{
Projeto de Objetos de Aprendizagem Para Educação Profissional Contra a Vulnerabilidade Social
}

\section{Learning Objects Project to Professional Education Against the Social Vulnerability}

\begin{abstract}
Resumo
O presente artigo propõe apontar aspectos que devem ser observados no projeto e construção de Objetos de Aprendizagem (OA) para sujeitos adictos em crack, pós tratamento clínico e que se encontram em vulnerabilidade social. Tais aspectos foram construídos baseando-se em diversas pesquisas e entrevistas realizadas em uma investigação-piloto, objetivando balizar futuras pesquisas onde a aplicação das orientações contidas no objeto possam ou não colaborar na manutenção, retorno ou conquista de um posto de trabalho por parte do adicto. Sendo esse um significativo fator na ressocialização do sujeito, diminuindo suas recaídas e conseqüentemente fortalecendo a manutenção de sua abstinência. Os aspectos relevantes estarão demonstrados dentro do modelo OASIS - Objeto de Aprendizagem Significativa de Informação para Sociedade durante a construção de OA para este perfil.

Palavras-chave: Adictos. Crack. Interface. OASIS. Objetos de aprendizagem.
\end{abstract}

\section{Abstract}

This article aims to point features must be observed in the project and construction of Learning Objects (LO) to crack addicts, after undergoing medical therapy, and subject to social vulnerability. These aspects were constructed based on several surveys and interviews conducted in a pilot experiment, aiming to determine future research in which the application of the guidelines contained in the object may or may not collaborate in the maintenance or achievement of a job position by the addict. This is a significant factor in the rehabilitation of individuals, reducing their relapse and therefore strengthening the maintenance to abstinence. The relevant aspects of the model will be demonstrated within OASIS - Objeto de Aprendizagem Significativa de Informação para Sociedade (Significant Learning Objects of Information for Society) during development of LOs for this profile.

Keywords: Addicts. Crack. Interface. OASIS. Learn objects.

ALBUQUERQUE, Rodney Cezar de; LIMA, José Valdeni de; DOLL, Johannes. Projeto de Objetos de Aprendizagem Para Educação Profissional Contra a Vulnerabilidade Social. Informática na Educação: teoria \& prática, Porto Alegre, v. 14, n. 2, p. 171-190, jul./dez. 2011.

\section{Rodney Cezar de Albuquerque José Valdeni de Lima \\ Johannes Doll \\ Universidade Federal do Rio Grande do Sul}

\section{Introdução}

Esta pesquisa versa sobre a aprendizagem profissionalizante de adictos em drogas ilegais, especificamente o crack, renovado em um cenário bem específico da contemporaneidade: a busca de um atalho possível que permita a dependentes químicos o encontro abreviado com a ressocialização. Pois, como quem se encontra em situação de vulnerabilidade social, especialmente pelo consumo de drogas, vive a plenitude da incerteza como cotidiano, e a abordagem aqui proposta entende que um atalho possível à ressocialização pode ser pelo mundo do trabalho.

O mundo do trabalho é criterioso, preconceituoso e cada vez mais especializado. E a comunhão do indivíduo com o mercado normalmente se dá pela educação, que por sua vez depende da cognição dos indivíduos enquanto no papel de aprendizes. Quando os sujeitos estão em uma situação de vulnerabilidade social, os elementos que compõem a cognição 
podem falhar, pois ela abrange itens como atenção, capacidade de aprendizado, memória, linguagem, noções espaciais, funções de execução (planejamento, metas e julgamento); imprescindíveis ao aprendizado. E drogas como o crack gradativamente degeneram os elementos que compõem as faculdades do que entendemos por cognição; um indivíduo com prejuízo cognitivo terá dificuldade em aprender, logo, se não aprende, terá maiores dificuldades em se manter em um posto de trabalho, ou em casos ainda mais extremos até mesmo em se inserir ou retornar ao mercado de trabalho.

Esse impasse parece insuperável, mas o presente trabalho percebe indícios de que os sujeitos que sobreviveram aos primeiros anos do crack, após acompanhamento profissional adequado, apoiados pelas TIC (acrônimo para Tecnologias da Informação e Comunicação), mais especificamente por um objeto de aprendizagem (OA) concebido com uma interface apropriada e pedagogia adequada, podem estar em um ambiente favorável ao surgimento de mudanças comportamentais que permitam o retorno gradativo ao convívio social, valendo-se deste objeto como uma ferramenta para romper esse forte e irresistível ciclo de dependência.

Por fim, o artigo descreve a técnica utilizada na construção das interfaces, personagens, além de todo o processo de criação dos mesmos. Por fim, são apresentados os resultados esperados e a aplicabilidade do projeto.

\section{Metodologia}

Este não é o primeiro e infelizmente não será o último projeto a utilizar uma abordagem onde se relaciona um programa de computador com sujeitos adictos. Para Williams, Silva e Pechansky (2007, p. 407): "O jogo demonstra ser útil para trabalhar crenças típicas de jovens usuários de drogas e promover estratégias de enfrentamento em situações de risco", ou seja, esse é mais um indício que reforça o uso das TIC como estratégia positiva no enfrentamento ao problema da drogadicção.

\subsection{Formulação do Problema}

Para Cervo e Bervian (2002, p. 84), "Problema é uma questão que envolve intrinsecamente uma dificuldade teórica ou prática, para qual se deve encontrar uma solução". Já Popper (apud LAKATOS; MARCONI, 2000) afirma que a primeira etapa da pesquisa cientifica está no surgimento do problema.

Surgido no início da década de 80 , o crack (conhecido popularmente como freebase, pedra ou rock), é um tipo de cocaína não refinada que, misturado a solventes e outros produtos químicos, gera uma pedra que é fumada em um cachimbo improvisado por seus dependentes. Sua venda e consumo, realizados em locais conhecidos no país como cracolândias, vêm experimentando largo crescimento nos últimos anos, sobretudo devido a seu baixo valor de comercialização, atualmente em torno de $\mathrm{R} \$ 3,00$ a pedra, e ao seu poderoso poder de dependência, fazendo com que a drogadicção se posicione como um relevante problema de saúde pública.

O recorte abaixo, sob um olhar pernambucano. A primeira xilogravura ilustra o cotidiano em uma cracolândia, onde se podem perceber pessoas fumando crack, o traficante vendendo a droga, uma pessoa morta e a vizinhança observando pela janela de suas casas, toda esta tragédia social que ocorre em sua frente. Já a outra xilogravura, representa o infinito trabalho da polícia de deter os menores e jovens adictos. Guardando as devidas proporções, ambos os recortes podem ser ampliados para centenas de cidades em todo o Brasil. 

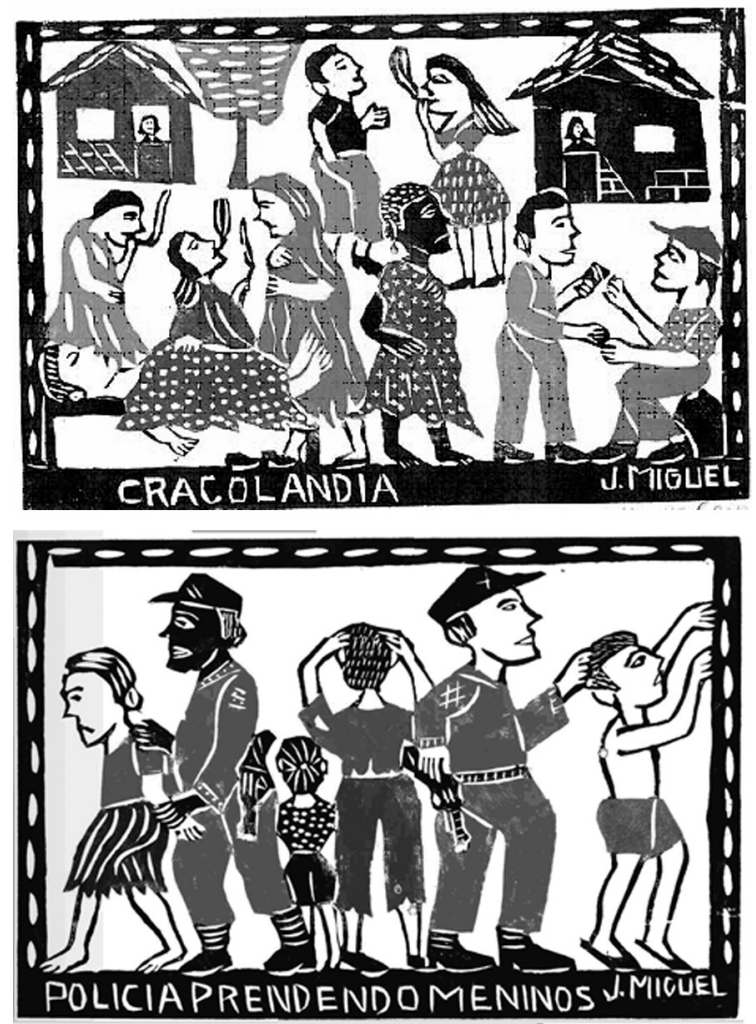

FIGURA 1 - Xilogravuras Assinadas Pelo Artista Pernambucano J. Miguel ${ }^{1}$

FONTE: Folha de São Paulo, 23 maio 2010, Cad. Ilustrissima, p. 3

Os textos e ilustrações anteriores apontam para um real problema contemporâneo, mas de forma muito distante e superficial. Para precisar ainda mais a percepção da problemática onde este projeto está inserido, faz-se necessário esmiuçar ainda mais a problemá-

10 artista pernambucano J. Miguel, 49 anos, vive e trabaIha em Bezerros, no Estado de Pernambuco. As xilogravuras dialogam com a tradição popular da arte visual do Nordeste. Na xilogravura, os desenhos são talhados em madeira e pintados à tinta, como se fossem carimbos. Estas foram feitas para acompanhar a reportagem A Encrenca do Crack, publicada no primeiro número do caderno Ilustríssima, feitas com exclusividade para o jornal Folha de São Paulo em 23 de maio de 2010. A primeira figura ilustra a dinâmica em uma cracolândia e a segunda figura ilustra a polícia prendendo meninos por conta do consumo de drogas. tica, pois o sujeito, adicto, está envolvido em um cenário de aprendizagem complexo, com muito mais elementos contra do que a favor, por isso imprescindível retornar um pouco a discussão apontando prováveis origens do problema, uma das portas de entrada; o consumo do álcool e a preocupante relação com as escolas.

\subsubsection{Uma porta de entrada}

Uma das portas de entrada ao consumo do crack pode estar na ingestão de bebida alcoólica na infância ou adolescência, não é possível afirmar que aqueles que consomem álcool nessa faixa etária, se tornarão adictos em crack, mas grande parte dos viciados em droga afirma ingestão de álcool na infância ou adolescência, tanto que aqueles que passaram pelo processo de recuperação são instruídos a não consumi-lo, pois o uso de álcool é apontado como um das grandes responsáveis pela recaída. Um dos locais onde se pode ter contato com as drogas lícitas ou ilícitas é a escola, conforme dados apresentados na figura 2

A amostragem acima é resultado de recente pesquisa realizada pelo CEBRID² com 5.226 alunos de ensino médio e fundamental de 37 escolas particulares da cidade de São Paulo; entre os entrevistados, $97,7 \%$ tinham entre 13 e 18 anos e $95 \%$ eram das classes A e B. $O$ baixo consumo de crack nas classes mais abastadas ratifica que esta droga faz-se pre-

\footnotetext{
2 O CEBRID é o Centro Brasileiro de Informações sobre Drogas Psicotrópicas, que funciona no Departamento de Psicobiologia da UNIFESP (Universidade Federal de São Paulo), antiga Escola Paulista de Medicina. Este centro ministra cursos e reuniões científicas sobre o assunto Drogas, publica livros, faz levantamentos sobre o consumo de drogas entre estudantes, meninos de rua, etc. Fonte: http://200.144.91.102/ sitenovo/default.aspx A ilustração acima foi criada para acompanhar a reportagem 30\% dos Estudantes já se Embriagaram, publicada no caderno Cotidiano, do jornal Folha de São Paulo por Araújo em 8 de junho de 2010.
} 


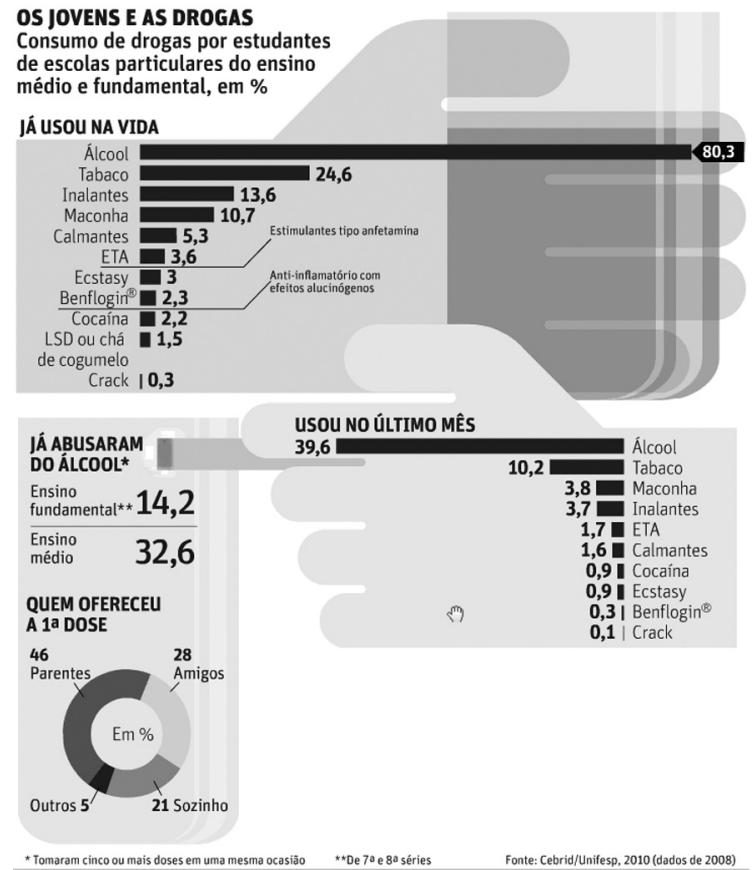

FIGURA 2 - Os Jovens e as Drogas

FONTE: Folha de São Paulo, 8 jun. 2010, Cad. Cotidiano, p. c3

sente nas classes mais baixas, e que chega a classe média.

A ilustração anterior aponta para que apenas $0,3 \%$ dos jovens estudantes das escolas particulares do ensino médio e fundamental de São Paulo já fizeram uso de crack, mas também faz-se necessário salientar que o álcool é consumido por $80,3 \%$ da amostra, sendo apontado pelos próprios dependentes químicos em recuperação, além dos especialistas ouvidos durante a investigação-piloto deste projeto, como a porta de entrada ou da recaída.

Os dependentes químicos passam parte de suas vidas na drogadicção e para aqueles que conseguem trilhar o caminho da recuperação, junto com ela vem também a percepção do tempo perdido. A problemática onde este projeto está inserido procura identificar padrões desejáveis na construção de objetos de aprendizagem para adictos em drogas, em especial o crack.

Do ponto de vista da psicanálise, Freud (1969), conclui de que o princípio do prazer não era afinal a força mais poderosa, o autor apresenta forças que nos movem, as pulsões de Eros, que representam a energia da vida, reúne elementos impulsores da vida, apresenta ainda as pulsões de destruição, conhecidas como pulsão de morte. Para o autor esta estas pulsões estão em constante conflito. Todo conceito relacionado a ressocialização, afastamento das drogas, utilização do OA para qualificação, está associado as pulsões de Eros, já a recaída ao consumo de drogas, toda auto-destruição promovida pelo vício, pode-se associar a pulsão de morte.

Além dos aspectos inerentes a psicanálise, uma vez em que se torne adicto em crack, faz-se necessário apresentar quais os mecanismos que prendem o cérebro do adicto em crack e por fim como a saúde pode ser prejudicada pelo uso contínuo da droga.

\subsubsection{Entendendo melhor o cérebro de um adicto em crack sob uma perspectiva clínica, potencial condição do sujeito desta pesquisa}

Como este projeto transpassa pela aprendizagem e considerando que essa ocorre no cérebro, e como esse se encontra em uma situação extrema, faz-se mister considerar também como problema da pesquisa os impactos negativos do uso da droga no cérebro, o que pode diretamente atrapalhar o desenvolvimento dos aprendizes.

Para melhor compreender o mecanismo de dependência do crack no organismo de um ponto de vista estritamente clínico, é imperativo primeiro entender o sistema de re- 
compensa cerebral ${ }^{3}$, para Formigoni, Kessler e Pechansky (2008), inúmeros estudos demonstraram que as drogas de abuso ou estímulos ambientais, reconhecidos pelo organismo como prazerosos, geram mudanças no cérebro, mais precisamente nas substâncias químicas chamadas neurotransmissores, responsáveis pela comunicação entre os neurônios.

Para os autores, as drogas de abuso agem sobre um número limitado de estruturas cerebrais. Essas regiões, nos seres humanos, são áreas corticais do cérebro ${ }^{4}$ e as vias mesolímbicas. Incluem, principalmente partes da área tegmentar ventral, que se comunicam por neurônios dopaminérgicos liberadores de dopamina ao núcleo accumbens e costumam intermediar as emoções reconhecidas como gratificantes ou prazerosas. O sistema que envolve esses circuitos cerebrais é chamado de sistema de recompensa cerebral.

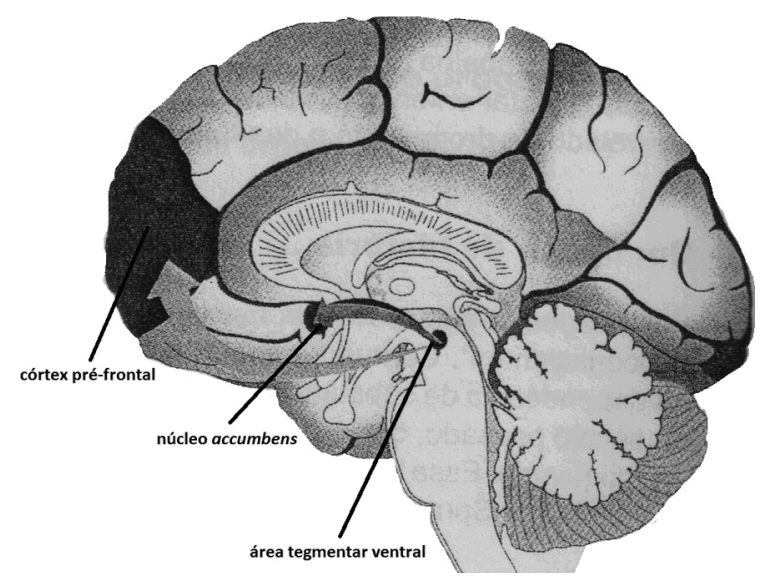

FIGURA 3 - Corte Longitudinal do Cérebro Apresentando o Sistema de Recompensa Cerebral

FONTE: Formigoni, Kessler e Pechansky, 2008, p. 4.

3 O sistema de Recompensa Cerebral é caracterizado por seus componentes centrais (núcleo accumbens, área tegmental ventral e córtex pré-frontal) e seu envolvimento com o sistema limbico (associado com as emoções) e com os principais centros responsáveis pela memória (amigdala e hipocampo).

4 Principalmente o córtex pré-frontal.
Formigoni, Kessler e Pechansky (2008, p. 5), afirmam que os Sistemas Neurais relacionados ao desenvolvimento da dependência de drogas como o crack seriam os mesmos do sistema de recompensa do cérebro ${ }^{5}$. A estimulação elétrica de determinadas áreas cerebrais causa prazer (humanos) e provoca autoestimulação (animais). Estas áreas produzem sítios de ligação (receptores ou canais iônicos) aos quais se ligam as drogas de abuso. Antagonistas destes receptores reduzem os efeitos reforçadores tanto de recompensas naturais, como a da estimulação cerebral e a do prazer decorrente da administração de drogas.

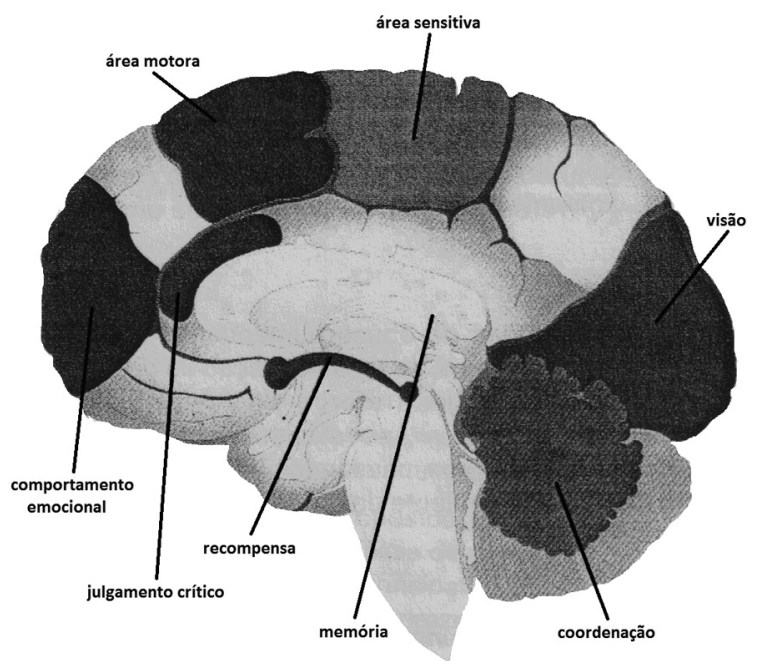

Figura 4 - Corte Longitudinal do Cérebro Apresentando nas Partes Mais Escuras o Sistema Límbico

FONTE: Formigoni, Kessler e Pechansky, 2008, p. 5

O termo reforço, bastante usado nessa área, refere-se a um estímulo que fará com que um determinado comportamento ou resposta se repita, devido ao prazer que causa (reforço positivo), ao desprazer ou desconforto que alivia (reforço negativo). Por exemplo:

5 Principalmente vias dopaminérgicas mesolímbica e mesocortical. 
quando se come uma comida deliciosa (bombom de chocolate,...), mesmo sem se estar com fome, a comida é um reforço positivo. Quando você come uma comida que não gosta, somente porque está com muita fome e aquela é a única comida disponível, a comida é um reforço negativo, porque alivia uma sensação ruim, de desconforto - a fome.

Como as drogas de abuso aumentam a liberação de uma substância neurotransmissora a dopamina - no núcleo accumbens - que causa uma sensação de prazer, as pessoas podem usar drogas porque querem sentir uma sensação de bem-estar, de alegria (reforço positivo) Formigoni, Kessler e Pechansky (2008, p.6). Mas elas também podem usar drogas porque estão tristes, deprimidas ou ansiosas e querem aliviar estas sensações ruins - neste caso, procuram na droga o reforço negativo. Esta propriedade reforçadora da droga, causando prazer ou aliviando sensações ruins (por exemplo, a síndrome da abstinência de quem é fisicamente dependente da droga), aumenta a chance da reutilização da droga.

Os autores reforçam ainda que quando uma droga é administrada repetidamente e não provoca mais o mesmo efeito, ou é preciso aumentar a dose para ter a mesma sensação, diz-se que a pessoa está tolerante àquele efeito da droga. Este fenômeno, a tolerância, é comumente encontrado nas pessoas que se tornam dependentes das drogas. Isto é relativamente comum com drogas depressoras como benzodiazepínicos, barbitúricos e altas doses de álcool.

Em Registros em Arquivos apresenta o Gráfico de Setores: Dano que é um resumo dos registros médicos do banco de dados da ONG PACTO/POA relativo ao prejuízo cognitivo dos dependentes de drogas, relacionando ainda com a escolaridade dos entrevistados.

Agora que foram apresentados os mecanismos que prendem o cérebro de um adicto ao crack, finalmente, faz-se necessário apresentar como a saúde pode ser atingida pelo uso contínuo da droga.

\subsubsection{Entendendo melhor o possível estado de saúde de um adicto em crack, potencial condição do sujeito desta pesquisa}

O estado de saúde do aprendiz, sujeito desta pesquisa, não pode ser desassociado do objeto a ser aprendido, pois mesmo que os sujeitos abandonem seu vício, o crack pode deixar sequelas profundas em seus usuários. E essas sequelas necessitam também ser consideradas em uma turma de adictos em crack, pois esses problemas também possuem grande potencial em atrapalhar a aprendizagem.

Para Cruz e Felicíssimo (2008 p. 75), os usuários de crack estão expostos aos mesmos riscos que os usuários da cocaína, além dos riscos relacionados à agressão ao sistema respiratório por inalação de fumaça tóxica em alta temperatura. Podem apresentar dor, tosse, hemoptise ${ }^{6}$, bronquite, asma, pneumonia e edema pulmonar. É característica a ocorrência do pulmão de crack, sintomas de pneumonia sem evidências de infecção na radiografia de tórax.

Como os riscos são os mesmos dos usuários de cocaína, esses estão concentrados principalmente no sistema cardiovascular (CRUZ; FELICÍSSIMO, 2008, p. 74). O efeito estimulante da droga, somado ao bloqueio de canais de cálcio nas células cardíacas, altera o ritmo sanguíneo para o coração, o que pode ocasionar arritmias cardíacas ${ }^{8}$, hipertensão arterial e contrações das artérias que podem

6 Escarro de sangue.

7 Dor intensa no tórax, febre alta, dificuldade para respirar.

8 Taquicardia, extrassístoles, fibrilação e asistolia. 
levar a isquemias ${ }^{9}$ e infarto do miocárdio.

Por fim, os autores ainda salientam que o cérebro também pode ser atingido por problemas de origem vascular, que causam ataques isquêmicos transitórios e acidentes vasculares cerebrais, que podem deixar seqüelas motoras e cognitivas. O efeito tóxico direto e continuado da droga sobre o cérebro pode aumentar as chances de o indivíduo apresentar convulsões e múltiplos infartos silenciosos, que levam a prejuízos da memória de longo prazo.

O consumo de crack leva a um elevado risco de vida. Em alguns casos, fora relatado durante as entrevistas da investigação-piloto deste projeto que apenas quando o sujeito percebeu os indícios aparentes inerentes ao risco de vida, é que o mesmo buscou auxílio profissional e internação para tratar do problema. Quando essa ajuda se encontra disponível. Ou seja, em alguns casos esses problemas de saúde gerados pelo consumo da droga, podem estar sendo vividos pelos sujeitos durante a realização desta pesquisa.

Pode não parecer que a manutenção, retorno ou conquista de um posto de trabalho seja um grande problema, mas para um adicto efetivamente é, pois os mecanismos de seu vício, como explicado anteriormente, em alguns casos, é muito mais potente do que sua disciplina para acordar no horário para ir ao trabalho ou tomar banho; a responsabilidade pode falhar e essa mudança de comportamento necessita ocorrer, pois geralmente os patrões não toleram frequentes faltas, atrasos e irresponsabilidades.

Ações aparentemente inofensivas como ir a festas, eventos sociais ou até mesmo reuniões familiares, podem ser um exemplo de provação de fé para um adicto em drogas, pois o consumo de bebida alcoólica é deter-

9 Diminuição da quantidade de oxigênio transportado pelo sangue até os órgãos. minante na recaída ao consumo da droga, e uma simples festa de batizado possui alta potencialidade de permitir a recaída ao consumo da droga.

Ressalta-se, portanto, que o problema a ser pesquisado pelo presente projeto está na dificuldade da mudança de comportamento, ressocialização e na manutenção, retorno ou conquista de um posto de trabalho para sujeitos adictos em crack que passaram por algum tipo de tratamento clínico.

\subsubsection{Entendendo melhor o processo de recuperação em uma comunidade terapêutica}

Objetivando combater a dura realidade da drogadicção no Rio Grande do Sul, tanto ao auxiliar o dependente químico que deseja recuperar sua vida pregressa digna e saudável, quanto ao ajudar seus respectivos familiares, foi que em 8 de julho de 1989, voluntários fundaram a Pastoral de Auxílio Comunitário ao Toxicômano/Porto Alegre (PACTO/POA), transformada em ONG alguns anos depois.

Através de sua casa de triagem, localizada na região central de Porto Alegre, o dependente químico dá o primeiro passo no sentido de mudar sua dura realidade. Após a realização dos exames médico e odontológico, o candidato é submetido à avaliação psicológica, ao tempo em que seu responsável é entrevistado por um assistente social. Desde que não seja constatado nenhum impedimento, sua internação é permitida, para que o candidato seja encaminhado à realização de seu programa de recuperação. Os primeiros quinze dias são destinados a um período de desintoxicação, realizado na casa de triagem. Em seguida o dependente químico é encaminhado à comunidade terapêutica.

Springer (2008, p. 107) define uma comunidade terapêutica como sendo um ambiente 
de tratamento residencial onde mudanças de conduta, atitudes, valores e emoções do usuário de drogas são implementadas, monitoradas e reforçadas diariamente.

A comunidade terapêutica iniciou suas atividades em 29 de setembro de 1990, dia do Arcanjo São Miguel, na denominada Fazenda do Senhor Jesus, no distrito de Lomba Verde, localizada no município de Viamão, distante $14 \mathrm{~km}$ da cidade de Viamão e $44 \mathrm{~km}$ do centro de Porto Alegre, e recebe para internação, majoritariamente, jovens e adultos do sexo masculino.

Springer (2008) afirma que os defensores do AA (Alcoólicos Anônimos) acreditam que o alcoolismo é uma doença que não pode ser curada; portanto não existem ex-alcoólicos, mas sim alcoólicos em recuperação, essa mesma filosofia é aplicada aos dependentes químicos na metodologia de recuperação da PACTO/POA. Sua metodologia é apresentada em 12 passos.

Quando se encontram sujeitos em uma comunidade terapêutica, vivenciando os passos do $A A$, e que através deles reencontram progressivamente o reencantamento do mundo; para Prigogine (2002) a ciência pode contribuir para diminuir as desigualdades, quando afirma:

Ela contribui para isso, não há dúvida nenhuma! Não há dúvida de que foi o desenvolvimento tecnológico, especialmente o universo das comunicações, a televisão e muitas outras realizações, que permitiram essa regressão da noção de desigualdade. Certamente, a ciência desempenha um papel fundamental nessa evolução [...] (PRIGOGINE, 2002, p. 72).

Melhor explicando os passos pode-se afirmar que:

Nos 'passos de entrega' a equipe de tratamento trata de persuadir o jovem de que ele não pode controlar seu uso de drogas. Os jovens 'entregam' suas tentativas de controlar o uso de drogas a um poder mais alto. O 'poder mais alto' não é sempre sinônimo de Deus ou alguma divindade, e a ênfase está em criar uma defesa espiritual contra o uso de drogas. Os 'passos de integridade' tem o objetivo de ajudar o jovem a admitir que causou danos a outros, permitindo, assim, que ele aceite responsabilidade pessoal por conflitos precipitados pela tensão que envolve o uso de drogas e álcool (BROWN-STANDRIDGE apud SPRINGER, 2008, p. 113).

Após nove meses de internação, período durante o qual todos os residentes foram submetidos ao processo que segue o método Minesota (utilizado pela Day Top Vilage, latinizado pelo projeto Huomo, que busca o desenvolvimento da espiritualidade através da vivência do tripé: oração, trabalho e disciplina), o dependente químico está preparado para reviver sua vida de forma digna e saudável. Mas infelizmente, algumas vezes, por falta de uma atividade profissional, o dependente químico, já em contato com a sociedade, retoma o uso da droga.

Ressalte-se que durante os 9 meses os dependentes químicos em recuperação realizam visitas, e que no retorno realizam o teste de urina. Springer (2008) afirma que nos Estados Unidos os exames de urina são usados no sistema judicial juvenil como método de vigilância para detectar se os infratores estão usando drogas. O sistema funciona da seguinte maneira: o integrante, quando retorna a comunidade terapêutica oriundo da visita, deve fornecer uma amostra de urina que é testada para detectar a presença de drogas específicas. O autor afirma que nos EUA os exames de urina para infratores possuem três objetivos comuns: (1) como complemento à supervisão comunitária, (2) como ferramenta de avaliação de infratores ingressando no sistema judiciário e (3) como avaliação do uso de drogas durante o tratamento de drogas compulsório (TIMROTS apud SPRINGER, 2008).

Pode-se pensar nas 3 ecologias de Guattari (1990) e pensar em uma releitura, contra- 
pondo o tripé de recuperação dos adictos. A mesma busca em como viver daqui em diante; quando traduzido em uma escala pessoal, pode-se pensar na oração levando-se em conta toda a força da subjetividade humana; podese realizar um paralelo do trabalho do tripé, com as relações sociais e da disciplina, com o meio ambiente. Guattari (1990) afirma que os modos de vida humanos individuais e coletivos evoluem no sentido de uma progressiva deterioração, onde as redes de parentesco tendem a ser reduzir ao mínimo: à vida doméstica que vem sendo gangrenada pelo consumo da mídia, à vida conjugal e familiar que se encontra frequentemente ossificada por uma espécie de padronização dos comportamentos, as relações de vizinhança estão geralmente reduzidas a sua mais pobre expressão. Todo este pano de fundo, ratifica a degradação promovida pela drogadicção.

O PACTO/POA passou a buscar novas alianças inovadoras e lança-se na missão de fechar o ciclo do processo de recuperação, profissionalizando seus egressos com cursos em diversas áreas. Imbuído de espírito inovador, será desenvolvido pelo LISEDUC do IFRJ um OA denominado OASIS, projeto disponibilizado sob licenciamento de software livre a ser distribuído em CD ou pela Internet, voltado ao ensinamento de técnicas de vendas, que será utilizado na educação profissional na modalidade de EJA em espaços da ENF. O software a ser desenvolvido atuará estritamente na área pedagógica do processo, enviando inclusive a seu usuário mensagens de auto-estima.

\subsection{Registros em Arquivos}

Objetivando identificar um ponto de partida, buscou-se criar um perfil mais generalizado dos sujeitos desta pesquisa; com esta meta, foi realizada na investigação-piloto a tabulação de registros em arquivos. Destaca-se que a fonte de dados utilizada em toda esta subseção, origina-se de informações inéditas coletadas no banco de dados tipo MS ACCESS ${ }^{\circledR}$ disponibilizado pela ONG PACTO/POA, RS, sistematizado desde 20 de maio de 1990.

Tal banco de dados é único, e totaliza 3.438 registros; mas, no momento da estratificação, houve o descarte de milhares de registros incompletos presentes para cada um dos distintos histogramas, gráficos e tabelas apresentados a seguir. Para melhor explorar as observações coletadas de forma que não influenciem na precisão dos dados, fora realizada uma filtragem para cada uma das amostras, essa precaução gerou distintas contagens tais como 422, 456 ou 2075 sujeitos. Isto justifica a utilização de amostras diferentes, apesar de estar tratando da mesma fonte de dados.

Todo tratamento foi realizado utilizando o software SEstatNet da UFSC. Segundo seus criadores, o SEstatNet é um ambiente flexível de ensino-aprendizagem de estatística por meio da internet. Disponibiliza e aplica procedimentos de descrição, estimação, testes de hipóteses e modelos de regressão para variáveis qualitativas e quantitativas.

A Topologia utilizada até o momento é a do teste de hipóteses que possui a seguinte estrutura:

1. Declaração do conjunto específico de hipóteses do teste ( $\mathrm{HO}$ e $\mathrm{H} 1)$;

2. especificação do nível de significância a da pesquisa;

3. obtenção da medida estatística do teste

4. obtenção da probabilidade de significância ( $p$-valor) utilizando uma distribuição de referência;

5. aplicação da regra de decisão do teste;

6. conclusão estatística.

Estatísticas Descritivas: Dos 462 sujeitos desta amostra, 422 são representados na ta- 
bela abaixo por $\mathrm{n}$, e significa o uso de múltiplas drogas, já os outros 40 sujeitos representados na tabela abaixo por 1 representam o uso de apenas uma única droga.

Abaixo é apresentado um diagrama de caixas, onde se apresenta uma aproximação entre aos usuários de múltiplas drogas e uma única droga. Percebe-se, em ambos os casos, que a idade dos sujeitos está entre 21 e 34 anos.

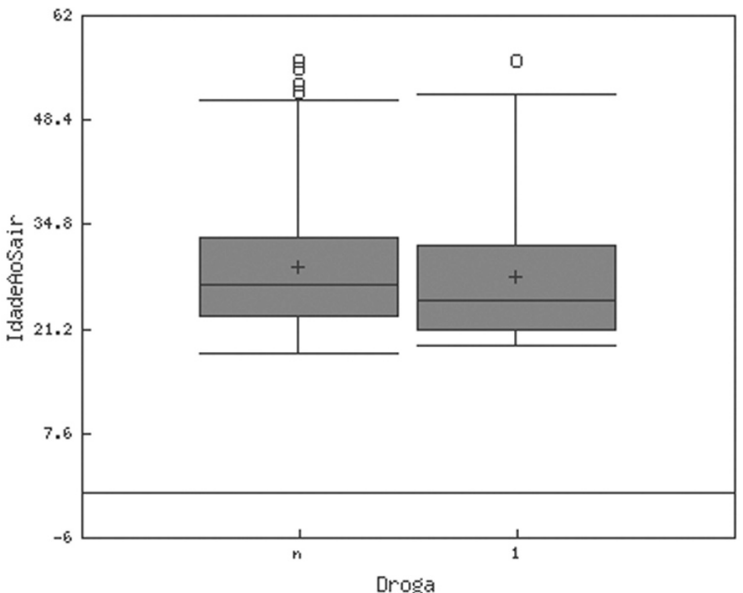

GRÁFICO 1 - Diagrama de Caixas Demonstrando a Idade ao Sair das Drogas X Quantitativo de Drogas Usadas. FONTE: Albuquerque e Doll, 2011, p. 32.

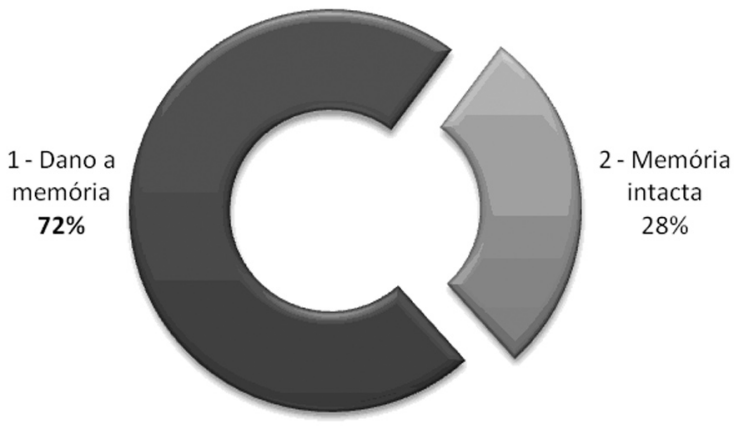

GRÁFICO 2 - Gráfico de Setores Sobre o Dano a Memória Pelo Uso das Drogas

FONTE: Albuquerque e Doll, 2011, p. 33

Percebe-se que dos 456 sujeitos desta amostra, 128 sujeitos não apresentaram du- rante os exames médicos prejuízo à memória; já dos 328 sujeitos observados, ou seja, em $71,93 \%$ ocorre o dano à memória decorrente do uso da droga.

\subsection{Entrevistas}

Dando continuidade a metodologia da coleta de evidências na condução de estudos de caso, será apresentada a terceira das fontes citadas por Yin (2005) utilizadas nesta pesquisa, as entrevistas. Toda investigação-piloto deste projeto, deu-se em uma ONG de Porto Alegre; e, através de entrevistas e diálogos com 34 sujeitos, foi possível perceber indícios que devem ser observados na construção de objetos de aprendizagem para adictos em cra$c k$. Abaixo serão apresentados dados tabulados, a fonte de dados utilizada em toda esta subseção se origina de encontro realizado no $2^{\circ}$ semestre de 2009.

TABELA 1 - Nível de Conhecimento em Informática

\begin{tabular}{|c|c|}
\hline Nível de conhecimento & $\%$ \\
\hline Não sabe informática & $35,29 \%$ \\
\hline Nível inicial de informática & $50 \%$ \\
\hline Nível médio de informática & $11,76 \%$ \\
\hline Nível avançado de informática & $2,94 \%$ \\
\hline
\end{tabular}

FONTE: Albuquerque e Doll, 2011, p. 33.

\section{OASIS}

Diversos meios inspiradores podem ser utilizados durante um processo de criação. Reunir todos os conteúdos aos quais se pesquisou e transportá-los para os cadernos de desenho é um meio bastante eficiente. Pois permite primeiramente listar as características dos personagens, tais como: suas atitudes, vestes, a linguagem oral e corporal, entre outros 
elementos que compõem o aspecto geral de um personagem. Para este projeto, a inspiração foram os próprios adictos em crack.

A identificação através das características dos adictos, sobretudo em relação ao aspecto visual é significativa, pois ao se reconhecer, esta ação pode colaborar na auto-estima e permitir maior atenção em relação aos conteúdos apresentados. Esta estratégia busca canalizar a atenção do sujeito ao conteúdo abordado, pois segundo Freire (1992) ensinar a aprender só é válido, quando os educandos aprendem a aprender ao aprender a razão de ser do objeto ou do conteúdo.

Dito isto, as pesquisas realizadas na investigação-piloto apontaram para a construção de um personagem de 26 anos, conforme apresentado no histograma IdadeAoSair $x$ Droga $=n$ sobre Registros em Arquivos, esta informação associada a entrevistas e outras percepções presenciais foram preponderantes na construção dos personagens. As próximas seções irão apresentar a proposta OASIS para uma interface apropriada a adictos e a pedagogia adequada a ser abordada para este tipo de software.

\subsection{OASIS - Técnicas Utilizadas na Construção da Interface Apropriada Para Adictos}

Para a construção do OA serão utilizadas as metodologias do desenho industrial, fortemente baseadas em Bonsiepe e Gomes, este último professor e pesquisador radicado em Porto Alegre e voltado para a criatividade. A construção do objeto também lançará mão da metodologia proposta por Meurer e Szabluk (2009) no Projeto $E$, que é especifica para projetos gráficos e virtuais, como web, softwares, etc. Tal metodologia é dividia em: estratégia, escopo, estrutura, esqueleto, estética e execução, detalhadas a frente.

\subsubsection{Estratégia}

Dentro da metodologia, é necessário interrogar para identificar, pois esta parte do método busca identificar eventuais dúvidas na construção do OA. Abaixo, são apresentadas as perguntas e as respostas atribuídas:

O que desenvolver? Projeto para desenvolvimento de $\mathrm{OA}$ animado.

Por que projetar? Para servir como instrumento de profissionalização de adictos.

Para quem? Para projeto de pesquisa em Iniciação Cientifica do CNPq pelo IFRJ como parte da presente pesquisa.

De onde? Bolsista residente em Porto Alegre, RS para a investigação-piloto.

Com que tecnologia? Execução das personagens e cenários em programa gráfico vetorial Adobe IIllustrator CS4® e animação destes em Adobe Flash CS4®.

Para que mercado? Para o mercado nacional. O usuário irá ter a opção em escolher sua região o que definirá o cenário do objeto.

Como desenhar? O desenho do OA será concebido tomando como base a metodologia projetual proposta por Bonsiepe et al. (1984), além das especificações do Projeto $E$ de Meurer e Szabluk (2009).

Como irá fazê-lo? Através da metodologia de projeto proposto por Bonsiepe (1984), do processo criativo proposto por Gomes (2001) e a utilização de programas gráficos vetoriais e de animação. É fundamental, para o êxito do projeto, o pleno conhecimento de aonde se pode chegar, considerando-se todas as possibilidades, requisitos e restrições.

Onde está e aonde poderá chegar

A construção dos personagens e do próprio OA deu-se a partir de entrevistas, seguindo a metodologia de projeto em Desenho Industrial/Design. Esta metodologia é fundamentada a partir da definição real do problema do projeto. Que deve ser feito, para quem, como, 
por quê e em quanto tempo este projeto deve ser realizado.

Seguindo esta metodologia, a problematização se definirá da seguinte forma:

o que seria o projeto? Desenho de projeto de personagem animado para utilização de OA ilustrativo.

Por que o fazes? OA para guiar e ensinar/ educar usuários com baixa cognição, usuários drogadictos e egressos de programa de tratamento, com o propósito de profissionalizá-los usando recursos de vídeos-aula dentro do OA.

A situação real do problema do projeto se define como sendo:

\section{Situação Inicial Bem Definida}

Desenho de projeto de personagem animado para OA. Projeto de desenho de OA animado tendo como usuários adictos em crack. Estes serão profissionalizados pelo $O A$ que contém diversas aulas em vídeo.

\section{Situação Final Bem Definida}

Construção de OA para toxicômano em fase de tratamento. Sistema de aprendizagem por meio de aulas em vídeo, mediadas, por um personagem interativo construído com recursos computacionais. Segundo esta metodologia de construção, uma vez determinada a problemática, segue-se para a etapa de pesquisa do estado-da-arte dos sítios que contenham OA similares ao que se pretende construir, pois desta forma podem-se identificar diferentes tipos de softwares existentes, analisando suas características, funcionalidades e carências, a fim de aperfeiçoar o produto ora proposto, um OA com uso de personagens no formato de animação 2D, que lança mão de personagens interativos, cativantes e interface gráfica amigável.

Para a construção dos personagens, estudou-se o perfil desses usuários por meio de entrevistas com a psicóloga e a assistente social da ONG PACTO/POA, durante a investigação-piloto do projeto, para entender melhor os gostos, preferências, linguagens com as quais esses usuários se identificam.

Percebeu-se grande similaridade desses usuários com o meio urbano. É nesse ambiente social no qual a maioria se desenvolve, cria seus vícios, comportamento, suas linguagens e suas maneiras de protestar, de se expressar e reivindicar para com a sociedade.

Após esta identificação, definiu-se então que tanto a interface gráfica quanto as características dos personagens, deveriam ser baseadas nesse estilo ou movimento urbano contemporâneo.

Os personagens animados serão o principal condutor dos conteúdos apresentados pelo software e irão interagir com o usuário por meio de explicações do conteúdo através de balões de fala. O OA permitirá navegação por menus e aprendizagem de conteúdos propostos pelo programa de maneira interativa, divertida e interessante para os usuários. Esta metodologia entende que não basta simplesmente ter bons conteúdos, se a navegação for complicada o sistema pode se desinteressante para o adicto; que, conforme explicado em Registros em Arquivos, registra prejuízo cognitivo devido ao consumo de crack.

Optou-se por utilizar, como estratégia de aproximação, a apresentação de elementos identificados como próximos à realidade de um sujeito em uma condição de vulnerabilidade social, visando criar uma espécie de afetividade ou amizade com o usuário, visto que a maioria destes possui pouca familiaridade com o computador.

O que foi considerado

Fatores projetuais: Gomes (2001) classifica 9 fatores que devem ser equacionados em um projeto de produto, e o Projeto $E$ de $\mathrm{Meu}$ rer e Szabluk (2009) os utiliza para identificar em que momento do projeto cada um será considerado, observando o ponto de vista do projetista de interface, do desenvolvedor e do 
usuário são eles: antropológicos, ecológicos, ergonômicos, econômicos, mercadológicos, tecnológicos, filosóficos, geométricos e psicológicos:

Antropológicos: Auxiliar a forma de se projetar OA para adictos

Ecológicos: Otimizar energia

Ergonômicos: Facilidade de uso

Econômicos: Meio mais barato de aprendizagem

Mercadológicos: Renda para o usuário

Tecnológicos: Primordial

Filosóficos: Inter-relação entre pessoas

Geométricos: Necessário para a usabilidade

Psicológicos: Fácil entendimento ao usuário

\section{Taxonomia}

Esta metodologia prevê a contextualização sobre a taxonomia e pode ser definida como uma forma consciente de criar foco no produto e situá-lo em um contexto mais amplo, considerando sempre suas funcionalidades e a forma como será utilizado. A taxonomia é fortemente inspirada na sistematização biológica e divide-se em reino, filo, classe, ordem, família, gênero e espécie:

Reino: Desenho de interação

Filo: Informática

Classe: Animação

Ordem: Ambiente virtual

Família: $w w w$

Gênero: $O A$

Espécie: OA com personagens animados

Analisar, comparar, avaliar e refletir

No Projeto E, Meurer e Szabluk (2009) recomendam analisar de forma denotativa e conotativa a semântica de termos que identifiquem o OA. Abaixo será apresentado o levantamento denotativo segundo Ferreira (1999).

Denotativa

Personagem. [Do fr. personnage] S. f. e m. 1. Pessoa notável, eminente, importante; personalidade, pessoa. 2. Cada um dos papéis que figuram numa peça teatral ou filme, e que devem ser encarnados por um ator ou uma atriz; figura dramática. 3. P. ext. Cada uma das pessoas que figuram em uma narrativa, romance, poema ou acontecimento. 4. P. ext. Ser humano representado em uma obra de arte: O guerreiro é a personagem mais expressiva do quadro.

Adicto. [Do lat. addictu] Adj. 1. Adjunto, adstrito, dependente. 3. Med. Que não consegue abandonar um hábito nocivo, mormente de álcool e drogas, por motivos fisiológicos ou psicológicos. S. m. 4. Med. Indivíduo adicto (3).

Cognição. [Do lat. cognitione] S. f. 1. Aquisição de um conhecimento. 2. P. ext. Conhecimento, percepção. 3. Psicol. O conjunto dos processos mentais usados no pensamento, na percepção, na classificação, reconhecimento, etc. [Cf. cognação]

Interface. [De inter + face; ingl. interface] S. f. 1. Dispositivo físico ou lógico que faz a adaptação entre dois sistemas. 2. Conjunto de elementos comuns entre duas ou mais áreas de conhecimento, de interesse, etc.: Interface gráfica. Inform. Tipo de interface com o usuário (q. v.), em que a interação está baseada no amplo emprego de imagens, e não restrita apenas a textos ou caracteres, e que faz uso de um conjunto de ferramentas que inclui janelas, ícones, botões, e um meio de apontamento e seleção, como o mouse.

\section{Conotativa}

Na forma conotativa, lança-se mão de um painel semântico, que é uma forma de representação por diversas imagens conectadas ao tema proposto, conforme apresentado na figura 5 .

\section{Análise sincrônica}

A metodologia propõe realizar a análise sincrônica, que sugere fontes para busca de produtos semelhantes objetivando á realização de seleção, comparação e análise de OA 


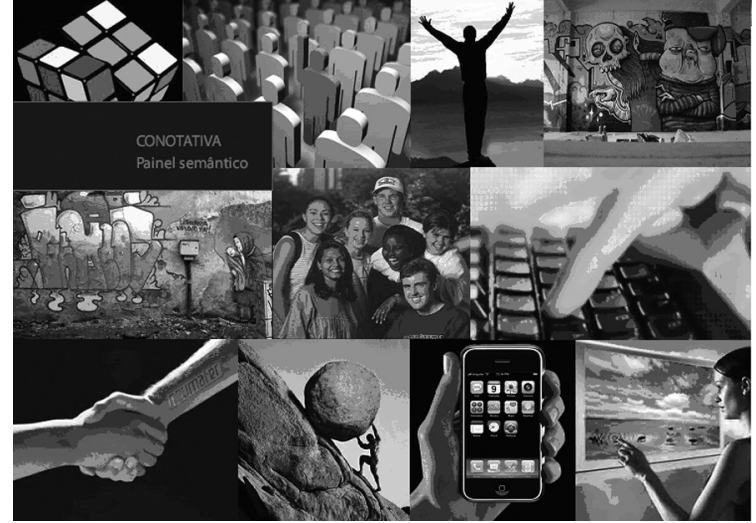

FIGURA 5 - Painel Semântico FONTE: Albuquerque e Doll, 2011, p. 35.

que possam servir de inspiração. As fontes de dados foram: o CESTA - Coletânea de Entidades de Suporte ao uso de Tecnologia na Aprendizagem da UFRGS, INTERED - Aprendizagem Compartilhada em Rede, o Portal do Professor do MEC, o California State University Center for Distributed Learning (CSU-CDL) e o Proyecto Arca - Federación de metadatos sobre contenidos multimedia y retransmisiones programadas.

Diferencial semântico

Segundo Memória (2005), o diferencial semântico identifica, classifica e compara diferentes características marcantes nos produtos analisados. A tabela 2 apresenta a síntese com as características do OA.

Análise funcional

A metodologia propõe a identificação das funções do produto; pois, para a construção do objeto, deverá haver uma abordagem anterior sobre o seu funcionamento, essencialmente sobre os controles padrão para operações em ambiente multimídia: executar, parar, avançar, e reproduzir.

Fluxograma

A seguir descreve-se um passo a passo da operação do usuário no $O A$.

1. Logo na introdução, a personagem Mãe
TABELA 2 - Características do Produto

\begin{tabular}{|l|c|c|r|}
\hline Textual & & $\mathrm{x}$ & Icönico \\
\hline Simples & $\mathrm{x}$ & & Complexo \\
\hline Poucas cores & & $\mathrm{x}$ & Muitas cores \\
\hline Objetivo & $\mathrm{x}$ & & Subjetivo \\
\hline Sério & & $\mathrm{x}$ & Divertido \\
\hline Estático & & $\mathrm{x}$ & Dinâmico \\
\hline Utilitário & $\mathrm{X}$ & & Entretenimento \\
\hline Clássico & & $\mathrm{x}$ & Contemporâneo \\
\hline Informativo & & $\mathrm{x}$ & Interativo \\
\hline
\end{tabular}

FONTE: Albuquerque e Doll, 2011, p. 35.

apresenta os dois personagens: Masculino e Feminino;

2. o usuário seleciona um dos personagens com o qual irá interagir durante sua aprendizagem;

3. o usuário atribui um nome ao personagem selecionado;

4. o usuário escolhe um dos cenários onde se passará a aprendizagem;

5. o personagem selecionado é introduzido no cenário escolhido;

6. o personagem se apresenta;

7. o usuário escolhe que vídeo deseja assistir;

8. ao terminar de assistir à vídeo-aula, o personagem realiza perguntas a respeito do conteúdo de vendas apresentado, buscando identificar e avaliar o que foi aprendido. Caso seja satisfatório, o personagem encaminha o usuário a outra fase ou permite ao mesmo assistir novamente à vídeo-aula para fins de fixação dos conteúdos.

\subsubsection{Escopo}

Geração de Alternativas - Técnicas de Criação dos Personagens 
Após apresentação da metodologia escolhida para o desenvolvimento do OA, será apresentado o passo a passo, da construção do software, durante as entrevistas da investigação-piloto foram coletadas as impressões que incidiram diretamente na construção do personagem.

Apesar do boné fazer parte da indumentária jovem, publico alvo deste projeto, durante o processo de criação dos personagens este instrumento de identificação fora abandonado por recomendação da assistente social. Pois, durante uma das entrevistas, foi evidenciado que drogadictos, em uma condição pregressa ao tratamento, buscam, exatamente esconder seus rostos usando óculos escuros e/ou bonés. Já no processo de ressocialização, fase onde será aplicado este $O A$, eles próprios usam uma expressão feliz de cara, representando esta nova vida. Sobretudo de cara limpa, onde não existe a necessidade de se esconder como na situação pregressa.

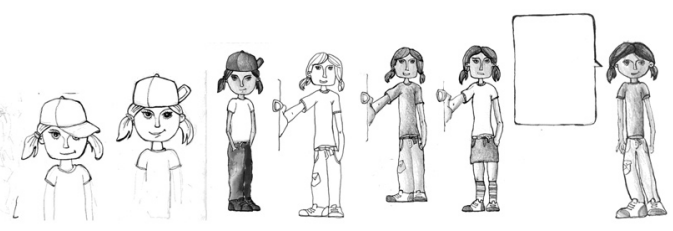

FIGURA 6 - Progresso no Desenvolvimento do Personagem Feminino

FONTE: Albuquerque e Doll, 2011, p. 35

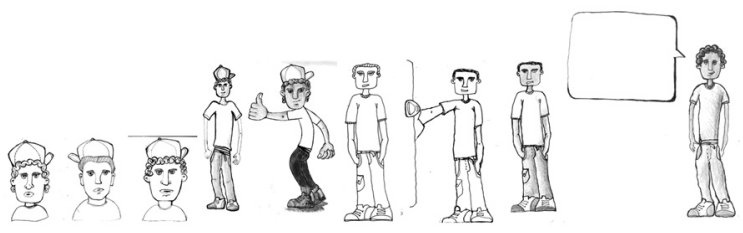

FIGURA 7 - Progresso no Desenvolvimento do Personagem Masculino

FONTE: Albuquerque e Doll, 2011, p. 35.

\section{Perfil dos Usuários do OASIS}

Foram identificados durante a investigação-piloto os seguintes aspectos por partes dos adictos:

- Estilo de vida ligado à cultura urbana;

- possuem linguagens próprias;

- usam vestimentas próprias.

Analisando essas informações, conclui-se que o personagem deve possuir características semelhantes, pois se espera que assim se possa criar eventual identificação com os usuários do sistema. Por diversas vezes, foi comentado sobre a relevância de uma condutora; pois, segundo o que foi relatado, os adictos chegam para tratamento, encaminhado por responsável do sexo feminino, parente ou familiar, normalmente mãe ou uma irmã mais velha. Por este motivo, fora agregado ao OA a figura de uma mulher mais velha, foi introduzido no sistema.
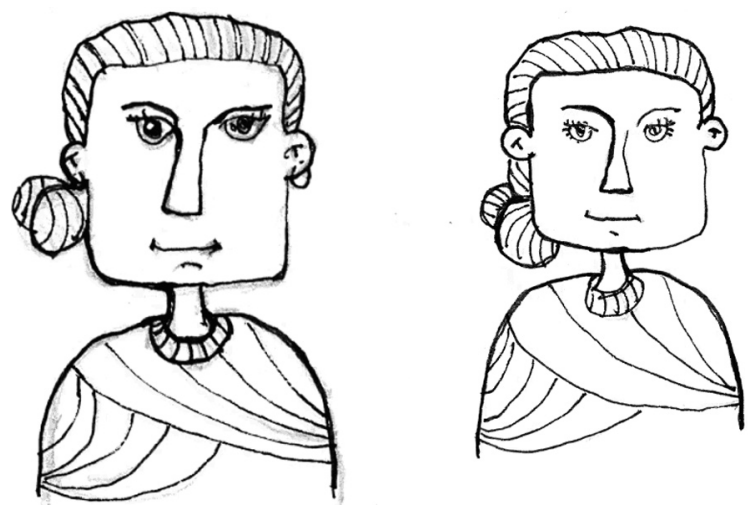

FIGURA 8 - Progresso no Desenvolvimento do Personagem Mãe FONTE: Albuquerque e Doll, 2011, p. 36.

Abaixo são apresentados os esboços iniciais da interface do OASIS, onde pode se observar que primeiramente havia se pensado em um relógio de rua, devido à fácil interação com o lugar geográfico onde seriam executados os conteúdos do objeto, mas este apresentou um problema, de onde entraria o menu. Pois um relógio de rua não possui menus. Observado isto, foi proposta uma alteração. 

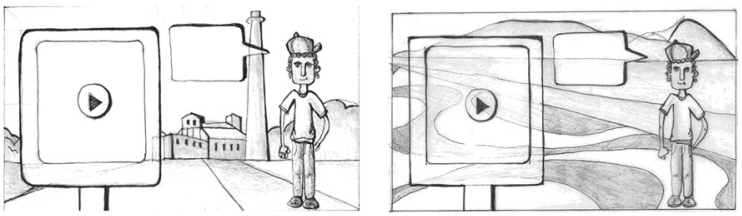

FIGURA 9 - Primeira Versão com o Relógio de Rua FONTE: Albuquerque e Doll, 2011, p. 36

Já na segunda versão da interface, sai o relógio de rua e entra um telefone, em primeiro plano; pois, neste tipo de interface, se apresenta facilmente o menu, disponível na interface de qualquer celular.
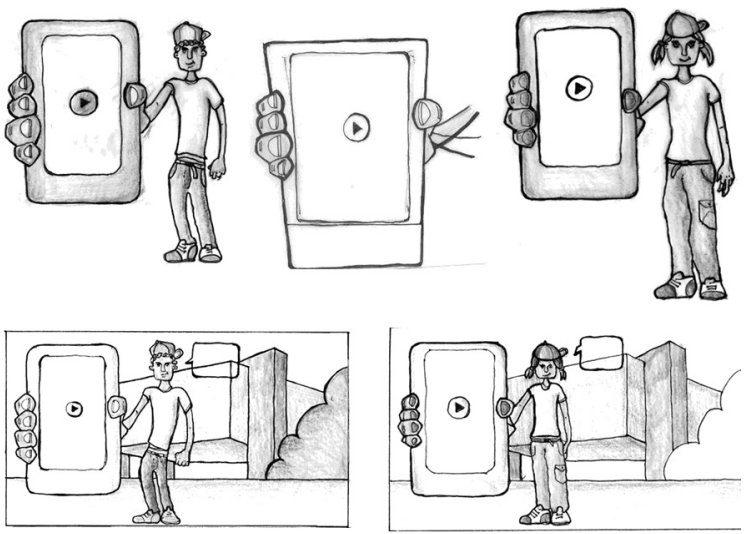

FIGURA 10 - Versão Final com o Telefone FONTE: Albuquerque e Doll, 2011, p. 36.

\subsubsection{Esqueleto}

Segundo a metodologia seguida faz-se necessária a construção de um esqueleto da interface, pois permite identificar com clareza onde cada um dos elementos estará disposto.

Malha

O primeiro elemento do esqueleto a ser apresentado é a malha de construção, que essencialmente serve para organizar as informações.

Personagem (RGB: 226, 101, 105): Como um dos maiores desafios da construção deste projeto está na composição das características dos personagens, estas não foram tão simples. Primeiramente foi necessário conhecer e analisar o público ao qual será direcionado a proposta. Saber quais os gostos destes usuários, para então partir para a criação. O maior desafio foi justamente compreender essas características e transportá-las para o papel, sem perder o foco no problema inicial desenvolvido no inicio do projeto. Criar algo diferenciado, porém que tenha uma identidade com a qual estes usuários possam, com facilidade, se identificar.

Balão de fala (RGB: 93, 153, 197): No OASIS, faz-se necessário estabelecer uma comunicação do usuário com o conteúdo, esta comunicação se dá pelo balão de fala. Pela linguagem, ao serem usados os balões, os personagens se apresentarão, farão a averiguação dos conteúdos a serem apresentados no vídeo.

Lugar geográfico (RGB: 209, 210, 212): Toda a animação acontecerá num determinado ambiente geográfico, que será definido primeiramente pelo usuário, a fim deste se familiarizar com o programa e ficar mais à vontade durante o consumo do conteúdo. De inicio serão três opções de cidades: Porto Alegre, São Paulo e Rio de Janeiro.

Abaixo é apresentado o esqueleto na malha.

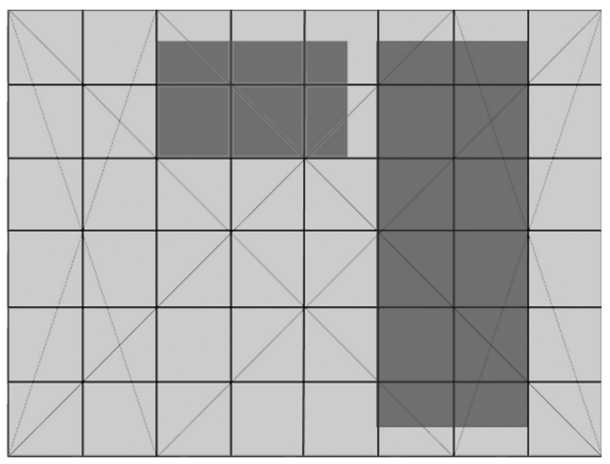

FIGURA 11 - Malha da Interface FONTE: Albuquerque e Doll, 2011, p. 37. 


\subsubsection{Estética - A identidade gráfico-visual}

\section{Tipografia}

A escolha das fontes tipográficas e das cores utilizadas no layout do objeto se deram do mesmo modo. Por análises e pesquisas e definição do conceito gráfico do objeto, que remetem à arte urbana e aos quadrinhos, os quais transmitem um conceito não formal e inspirador aos usuários.

A fonte escolhida para as falas do personagem com o usuário, que ocorrerão dentro do balão, foi no estilo das histórias em quadrinhos. Esse conceito de quadrinhos torna a aprendizagem divertida, porém sem perder o foco do projeto.

Para a outra fonte, do restante da interface gráfica do próprio objeto foi escolhida uma tipografia simples, não serifada, que permita fácil leitura em tela. Sabe-se da potencial dificuldade dos sujeitos na compreensão dos conteúdos, devido ao consumo da droga, portanto uma tipografia que não dificultasse esse aprendizado é de extrema importância.

É importante também lembrar que todo OA terá duas tipografias bem distintas. Uma delas simples e a outra mais característica, portanto cada uma delas possui papel importante na constituição do objeto. As fontes utilizadas no projeto são a Jester Regular e a Cantarell, abaixo apresentadas:

JESTER Regular - utilizada na fala dos personagens

abcdefghijklmnopqrstuvwxyz ABCDEFGHIJKLMNOPQRSTUVWXYZ $1234567890 .: ; i^{\prime \prime \prime}(! ?)+-* /=$

12 abcdefghijklmnopqrstuvwxya 1234567890
18 abcdefghijklmnopqrstuvwxyz. 1234567890

${ }_{24}$ abcdefghijklmnopqrstuvwxyz. 1234567890

CANTARELL - utilizada na interface gráfica do objeto

\footnotetext{
abcdefghijklmnopqrstuvwxyz ABCDEFGHIJKLMNOPQRSTUVWX $1234567890 . ., ;$ ' " (!?) +-*/=

12 abcdefghijklmnopgrsturwxyz. 1234567890

18 abcdefghijklmnopqrstuvwxyz. 1234567890

${ }_{24}$ abcdefghijkImnopqrstuvwxyz. 12345678 s
}

\section{Cromografia}

A escolha das cores utilizadas para compor o layout dos personagens, dos locais geográficos e da interface gráfica do $O A$, deu-se a partir de pesquisas e análises com os usuários e a partir de visitas ao meio em que vivem. Tendo em vista que alguns dos adictos possuem deficiências, transtornos por dependências químicas, a escolha correta das cores são de extrema importância, pois podem afastálos dessa realidade, passando ares positivos e inspiradores.

Para a escolha das cores das personagens, definiram-se matizes que remetessem á arte urbana, visto que essa expressão gráfica faz parte da realidade desses usuários, fato que foi constatado a partir da investigação-piloto. São essas cores fortes e vibrantes, que remetem á criatividade e motivação.

Para a escolha das cores dos locais geográficos, definiram-se matizes suaves, porém alegres, a fim de não interferir na importância que é dada à personagem no OA. É de extrema importância haver uma harmonia entre as cores, para que estas transmitam fácil aceitação visual; caso contrário, o design gráfico amigável não funciona.

Para a escolha das cores da própria interface do objeto, definiu-se uma cor que fosse instigante e ao mesmo tempo inspirasse os usuários para a aprendizagem. A cor azul definida para as pranchas de apresentação das personagens e dos locais de aprendizagem transmite tranqüilidade e confiança, virtudes que os usuários necessitam para realizar tal tarefa.

\subsubsection{Execução}

É nesta fase que se dará a passagem dos esboços e desenhos para a construção vetorial dos personagens.

Identidade gráfico-visual 
Na composição da identidade gráfico-visual, busca-se alcançar um modelo funcional para os personagens vetorizados. Abaixo são apresentadas a transposição tanto dos personagens quanto dos locais geográficos.

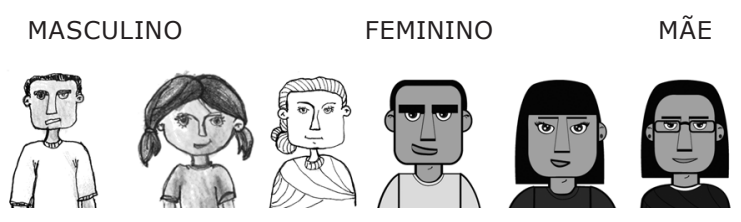

FIGURA 12 - Personagens vetorizados FONTE: Albuquerque e Doll, 2011, p. 37.

Neste momento está sendo criado um $3^{a}$ personagem, de gênero feminino, com idade entre 30 e 40 anos, que pode representar tanto a mãe ou irmã mais velha, que normalmente é quem apoia o dependente químico em sua recuperação. O objetivo deste personagem está no fato de ele criar um vínculo de respeito com o dependente e estendê-lo aos personagens já criados.

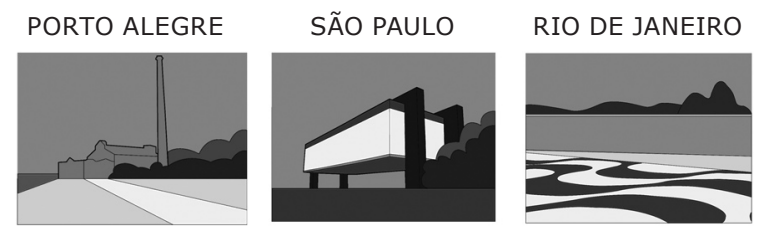

FIGURA 13 - Lugar Geográfico

FONTE: FONTE: Albuquerque e Doll, 2011, p. 38.

Por fim, a próxima figura que apresenta a composição completa, reunindo o lugar geográfico com o personagem e balão de fala permite apontar indícios que é relevante construir interfaces de Objetos de Aprendizagem para sujeitos adictos em vulnerabilidade social, como uma melhor forma de dialogar com estes sujeitos.

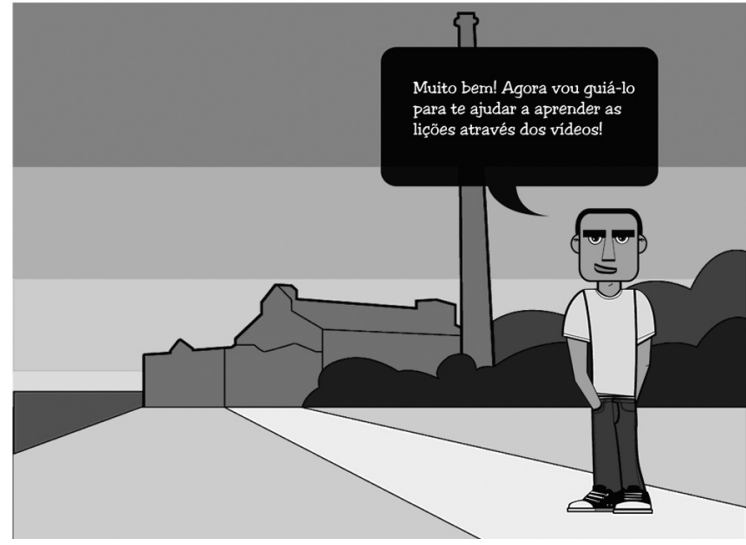

Figura 14 - Interface do OASIS

FONTE: FONTE: Albuquerque e Doll, 2011, p. 38.

\section{Trabalhos Relacionados}

Podem-se destacar duas pesquisas relacionadas ao assunto. Para Williams, Silva e Pechansky (2007, p. 407): "O jogo demonstra ser útil para trabalhar crenças típicas de jovens usuários de drogas e promover estratégias de enfrentamento em situações de risco", ou seja, esse é mais um indício que reforça o uso das TIC como estratégia positiva no enfrentamento ao problema da drogadicção. Por outro lado, destaca-se o trabalho de Del Pozo, Gomez, Fraile e Pérez (1998) intitulada Psychological and Behavioural Factors Associated with Relapse Among Heroin Abusers Treated in Therapeutic Communities, pois aborda aspectos comuns no tratamento em comunidade terapêutica em especial sobre a recaída no processo de recuperação, aspecto relevante a ser considerado neste tipo de trabalho científico.

\section{Considerações Finais}

Os pilares desta pesquisa estão na percepção de indícios de que a manutenção, re- 
torno ou conquista de um posto de trabalho possa colaborar positivamente neste esforço contemporâneo contra a drogadicção. Quando se trata de trabalho, a educação profissional possui papel significativo, sobretudo quando esta se vale das TIC em especial pós acompanhamento clínico especializado. No âmbito da aprendizagem, espera-se que este projeto amplie o uso de objetos de aprendizagem em espaços não formais na modalidade da educação profissional.

Por fim, espera-se que esta pesquisa relacionada ao modelo OASIS possa colaborar na construção de outros novos objetos de aprendizagem com foco na ressocialização de sujeitos em elevada vulnerabilidade social, ressaltando-se ainda, que não se percebe destaque a esta temática na atualidade.

\section{Agradecimentos}

Nossos agradecimentos a ONG PACTO/POA por permitir realizar nossas pesquisas em suas dependências, ao apoio da Bolsista Barbara Tubelo e a CAPES Projeto STICAmsud LWM.

\section{Referências}

ALBUQUERQUE, R.C.; DOLL, J.; Aspectos Relevantes na Construção de Interfaces de Objetos de Aprendizagem para Sujeitos Adictos em Vulnerabilidade Social. Cadernos de Informática (UFRGS), v. 6, p. 32, 2011.

BONSIEPE, G. et al. Metodologia Experimental: Desenho Industrial. Brasília: CNPq/Coordenação Ed., 1984.

Cervo, A.L; BerViAn, P.A. Metodologia Científica. 5. ed. São Paulo: Prentice Hall, 2002.

CRUZ, M.S.; FELICÍSSIMO, M. SUPERA: Sistema Para Deteç̧ão do Uso Abusivo e Dependência de Substâncias Psicoativas: encaminhamento, intervenção breve, reinserção social e acompanhamento. Brasília: Secretaria Nacional de Políticas Sobre Drogas, 2008. Guia do Estudante. Módulo 2 - Efeitos de substâncias psicoativas no organismo. Problemas médicos, psicológicos e sociais associados ao uso abusivo de álcool e outras drogas.

DEL POZO, J.M.L.; GÓMEZ, C.F.; FRAILE, M.G.; PÉREZ, I.V. Psychological and Behavioural Factors Associated with Relapse Among Heroin Abusers Treated in Therapeutic Communities. Addictive Behaviors, Oxford, v. 23, no. 2, p. 155-169, 1998.

FORMIGONI, M.O.S.; KESSLER, F.; PECHANSKY, F. SUPERA: Sistema Para Detecção do Uso Abusivo e Dependência de Substâncias Psicoativas: encaminhamento, intervenção breve, reinserção social e acompanhamento. Brasília: Secretaria Nacional de Políticas sobre Drogas, 2008. Guia do Estudante. Módulo 2 - Efeitos de substâncias psicoativas no organismo. Neurobiologia: mecanismos de reforço e recompensa e o efeito biológico comum das drogas. 
FREIRE, P. Pedagogia da Esperança: um reencontro com a pedagogia do oprimido. 13. ed. Rio de Janeiro: Paz e Terra, 1992.

GOMES, L.V.N. Criatividade: Projeto-Desenho-Produto. Santa Maria: sCHDs, 2001.

GUATTARI, F. As Três Ecologias. 20. ed. Campinas: Papirus, 1990.

LAKATOS, E.M.; MARCONI, M. de A. Metodologia Científica. 3. ed. São Paulo: Atlas, 2000.

MEMÓRIA, F. Design Para a Internet: projetando a experiência perfeita. Rio de Janeiro: Elsevier, 2005.

MEURER, H.; SZABLUK, D. Projeto E: Metodologia Projetual Para Ambientes Dígito-Virtuais. In: INFODESIGN BRASIL | CONGRESSO BRASILEIRO DE DESIGN DA INFORMAÇÃO, 3., Rio de Janeiro, 2009. Anais. Rio de Janeiro, RJ: PUCRIO, 2009. P.1 - 6

PRIGOGINE, I. Do Ser ao Devir. São Paulo: UNESP, 2002.

SPRINGER, D.W. Revisão das Abordagens Terapêuticas Para Jovens Infratores Usuários de Drogas nos Estados Unidos. Educação e Realidade, Porto Alegre, v. 33, n. 2, p. 99-122, 2008.

WILLIAMS, A.V.; SILVA, E.M. da; PECHANSKY, F. Desenvolvimento de um Jogo Terapêutico Para Prevenção da Recaída e Motivação Para Mudança em Jovens Usuários de Drogas. Psicologia: teoria e pesquisa, Brasília, v. 23, p. 407-414, jul./set. 2007.

YIN, R.K. Estudo de Caso: planejamento e métodos. Trad. Daniel Grassi. 3. ed. Porto Alegre: Bookman, 2005.

Recebido em maio de 2011.

Aprovado para publicação em julho de 2011.

\section{Rodney Cezar de Albuquerque}

Campus Avançado Engenheiro Paulo de Frontin - Instituto Federal do Rio de Janeiro (IFRJ) e Programa de PósGraduação em Informática da Educação, Universidade Federal do Rio Grande do Sul (UFRGS), Porto Alegre/ RS - Brasil. E-mail: rodney.albuquerque@ifrj.edu.br

\section{José Valdeni de Lima}

Programa de Pós-Graduação em Informática da Educação e Programa de Pós-Graduação em Ciência da Computação, Universidade Federal do Rio Grande do Sul (UFRGS), Porto Alegre/RS - Brasil.

E-mail:valdeni@inf.ufrgs.br

\section{Johannes Doll}

Faculdade de Educação, Universidade Federal do Rio Grande do Sul (UFRGS), Porto Alegre/RS - Brasil. E-mail: johannes.doll@ufrgs.br 